\title{
A New Validated Method for the Estimation of Olanzapine and Samidorphan Using High Performance Liquid Chromatography and of its Degradation
}

\author{
Syed Rafi*and Kantipudi Rambabu \\ Department of Chemistry, RVR \& JC College of Engineering, Chowdavaram, Guntur, Andhra Pradesh, India \\ Corresponding author email: rafiresearch2@gmail.com
}

\section{ABSTRACT}

New validated method for the estimation of Olanzapine and Samidorphan using HPLC and study of its degradation. Chromatographic separation was achieved on a symmetry C18 column $(150 \times 4.6 \mathrm{~mm}, 3.5 \mu)$ using isocratic elution with a mobile phase containing buffer and acetonitrile within the ratio of 60:40 as mobile phase with a flow of $1 \mathrm{ml} / \mathrm{min}$ at ambient temperature and UV detection was carried at $261 \mathrm{~nm}$. Analysis was achieved within 15 min over an honest linearity within the concentration range from $2-30 \mu \mathrm{g} / \mathrm{ml}$ of Olanzapine and $1-15 \mu \mathrm{g} / \mathrm{ml}$ of Samidorphan. By injecting the standard six times, system suitability parameters were studied and the outcomes were well under the acceptance criteria. Precision and recovery study results were found to be within the suitable limit. By using the above technique assay of marketed formulation was performed and found to be within the limit. Degradation studies were carried out on Olanzapine and Samidorphan, with a purity threshold greater than purity angle in all conditions and within the acceptable range. The above mentioned technique was validated according to ICH guidelines.

\section{KEY WORDS: HPLC, OLANZAPINE, SAMIDORPHAN, DEVELOPMENT, VALIDATION, DEGRADATION STUDIES.}

\section{INTRODUCTION}

Olanzapine, sold under the trade name Zyprexa among others, is an atypical antipsychotic primarily used to treat schizophrenia and bipolar disorder. For schizophrenia, it can be used for both new-onset disease and longterm maintenance. It is taken by mouth or by injection into a muscle. Common side effects include weight gain, movement disorders, dizziness, feeling tired, constipation, and dry mouth. Other side effects include low blood pressure with standing, allergic reactions, neuroleptic malignant syndrome, high blood sugar, seizures, gynecomastia, erectile dysfunction, and tardive dyskinesia. In older people with dementia, its use increases the risk of death. Use in the later part of pregnancy may result in a movement disorder in the baby for some time after birth. Although how it works is not entirely clear, it blocks dopamine and serotonin receptors. The chemical structure of Olanzapine was shown in figure 1.

Biosc Biotech Res Comm P-ISSN: 0974-6455 E-ISSN: 2321-4007
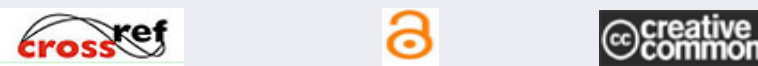

Identifiers and Pagination

Article Information

Year: 2021 Vol: 14 No (9) Special Issue

Received: 04 ${ }^{\text {th }}$ June 2021

Pages: 198-204

Accepted after revision: $19^{\text {th }}$ July 2021

This is an open access article under Creative

Commons License Attribn 4.0 Intl (CC-BY).

DOI: $h t t p: / / d x$.doi.org/10.21786/bbrc/14.9.38
Samidorphan (INN, USAN) (developmental code names ALKS-33, RDC-0313), also known as 3-carboxamido4-hydroxynaltrexone is an opioid antagonist that preferentially acts as an antagonist of the $\mu$-opioid receptor (MOR). It is under development by Alkermes for the treatment of major depressive disorder and possibly other psychiatric conditions. Samidorphan has been investigated for the treatment of alcoholism and cocaine addiction by its developer, Alkermes, showing similar efficacy to naltrexone but possibly with reduced side effects. However, it has attracted much more attention as part of the combination product ALKS-5461 (buprenorphine/samidorphan), where samidorphan is combined with the mixed MOR weak partial agonist and $\kappa$-opioid receptor (KOR) antagonist buprenorphine, as an antidepressant. Buprenorphine has shown antidepressant effects in some human studies, thought to be because of its antagonist effects at the KOR, but has not been further developed for this application because of its MOR agonist effects and consequent abuse potential.

By combining buprenorphine with samidorphan to block the MOR agonist effects, the combination acts more like a selective KOR antagonist, and produces only antidepressant effects, without typical MOR effects such as euphoria or substance dependence being evident. Samidorphan is also being studied in combination with olanzapine, as ALKS-3831 (olanzapine/samidorphan), 
for use in schizophrenia. A Phase 3 study found that the addition of samidorphan to olanzapine significantly reduced weight gain compared to olanzapine alone. The combination is now under review for approval by the US Food and Drug Administration. Figure 2 shows the structure of Samidorphan (Anderson \& Becker 2017).

Figure 1: Chemical structure of Olanzapine

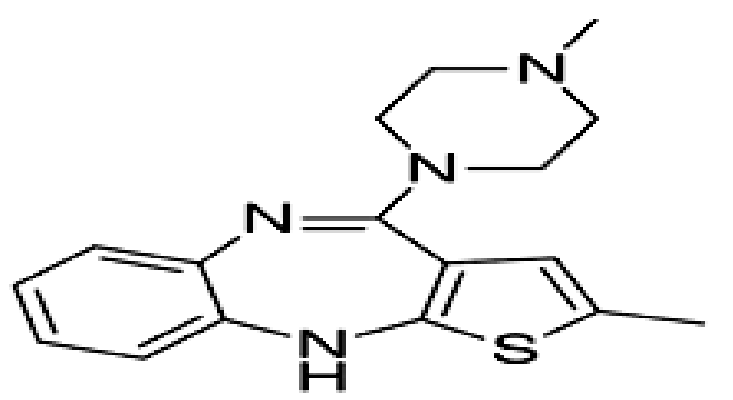

Figure 2: Chemical structure of Samidorphan

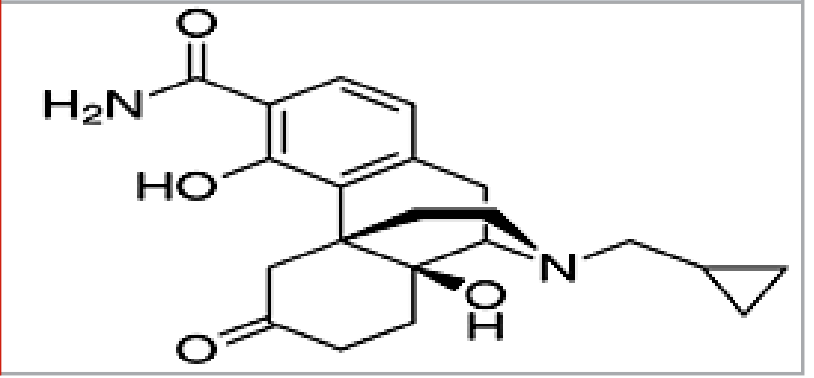

MATERIAL AND METHODS

2.1 Materials: Acetonitrile and ortho phosphoric acid, water (HPLC grade) were purchased from Merck (India) Ltd, Worli, Mumbai, India. All APIs of Olanzapine and Samidorphan as reference standards were procured from Laurus Labs Pvt. Ltd., Hyderabad.

2.2 Tools: An HPLC system (Waters alliance e2695 model) consisting of quaternary pump, PDA detector-2998 was used. Data processing was performed with Empower 2.0 software (Chatterjee et al., 2014).

2.3 Chromatographic conditions: Chromatographic separation was carried out in isocratic mode at room temperature using symmetry C18 column (150x4.6 $\mathrm{mm}, 3.5 \mu$ ). A mixture of acetonitrile and $0.1 \%$ ortho phosphoric acid (OPA) in 40:60 v/v at a flow of $1 \mathrm{ml} / \mathrm{min}$ was used as mobile phase. The injection volume was 10 $\mu \mathrm{l}$ and the run time was 10.0 min (Correll et al., 2020).

2.4 Preparation of buffer: $1 \mathrm{ml}$ of ortho phosphoric acid is dissolved in 1 lt of HPLC grade water and filtered through $0.45 \mu$ filter paper.

2.5 Diluent: Mobile phase was used as diluent.

2.6 Preparation of standard and quality control samples:
Accurately weigh and transfer $20 \mathrm{mg}$ of Olanzapine and $10 \mathrm{mg}$ of Samidorphan in $100 \mathrm{ml}$ volumetric flask and add app. $70 \mathrm{ml}$ of diluent, sonicate to dissolve it for 30 min. and made up to the mark with diluent. Furthur dilute $5 \mathrm{ml}$ of the above solution to $50 \mathrm{ml}$ with diluents.

2.7 Preparation of sample solution: Accurately weigh and transfer weight equivalent to $20 \mathrm{mg}$ of Olanzapine and $10 \mathrm{mg}$ of Samidorphan sample in $100 \mathrm{ml}$ of volumetric flask and add $70 \mathrm{ml}$ of diluent. Sonicate to dissolve and dilute up to the mark with diluent. Take $5 \mathrm{ml}$ of the above solution and diluted to $50 \mathrm{ml}$ and filtered through $0.45 \mu$ nylon syringe filter (Baizabal \&t Jankovic 2012).

\subsection{Method Validation}

2.8.1 System suitability: System suitability parameters were measured to verify the system performance. The parameters including USP plate count, USP tailing and \% of RSD are calculated and found to be within the limit.

2.8.2 Specificity: Specificity is the ability to assess unequivocally the analyte in the presence of other components, which may be expected to be present in the sample and standard solution. It was checked by examining the chromatograms of blank samples and samples spiked with Olanzapine and Samidorphan.

2.8.3 Accuracy: Accuracy is the closeness of the test results obtained by the method to the true value. It was assessed by the recovery studies at three different concentration levels. In each level a minimum of three injections were given and amount of the drug present, percentage recovery and related standard deviation were calculated (Carbon et al., 2017).

2.8.4 Precision: Precision of the analytical method is the degree of agreement among individual test results. It was studied by analysis of multiple sampling of homogeneous sample. The precision of the present method was assessed in terms of repeatability, intraday and inter-day variations. It was checked by analyzing the samples at different time intervals of the same day as well as on different days (Chisholm \& Mahesan 2017).

2.8.5 Linearity: Linearity of an analytical method is its ability to obtain results directly proportional to the concentration of the analyte in the sample within a definite range. The six series of standard solutions were selected for assessing linearity range. The calibration curve was plotted using peak area versus concentration of the standard solution and the regression equations were calculated. The least squares method was used to calculate the slope, intercept and correlation coefficient.

2.8.6 Stress degradation: Stress degradation should be no interference between the peaks obtained for the chromatogram of forced degradation preparations. Stress degradation studies were performed as per ICH guidelines Q1 (A) R2. The degradation peaks should be well separated from each other and the resolution between the peaks should be at least 1.0 and the peak purity of 
the principle peaks shall pass. Forced degradation studies were performed by different types of stress conditions to obtain the degradation of about $20 \%$.

2.8.7 Robustness: Robustness of an analytical procedure is a measure of its ability to remain unaffected by small but deliberate variations in method parameters and provides an indication of its reliability during normal usage. Robustness study was performed by injecting standard solution into the HPLC system and altered chromatographic conditions such as flow rate $( \pm 0.2 \mathrm{ml} /$ min), organic content in the mobile phase $( \pm 10 \%)$. The separation factor, retention time and peak asymmetry were calculated by determining the effect of the modified parameters (Healy et al., 2018).

\section{RESULTS AND DISCUSSION}

The current study was designed to develop a simple, precise and rapid analytical RP-HPLC method, which can be used for the analysis of assay method for simultaneous estimation of Olanzapine and Samidorphan in bulk and pharmaceutical dosage form. The chromatographic conditions were optimized in order to provide a good performance of the assay. To optimize mobile phase, various combinations were tried for Olanzapine and Samidorphan. The final working mobile phase is $0.1 \%$ tri ethyl amine and acetonitrile in the composition of 60:40 $\mathrm{v} / \mathrm{v}$. Mobile phase for each drug was selected based on its polarity. Detection was carried out in several wavelengths in order to obtain enough sensitivity for the two APIs in smaller proportion (Olanzapine and Samidorphan).

At last the wave length $261 \mathrm{~nm}$ was selected at which the two drugs showed good absorbance. The flow rate was $1.0 \mathrm{ml} / \mathrm{min}$. The retention time for Olanzapine and Samidorphan were $4.363 \mathrm{~min}, 7.732 \mathrm{~min}$ respectively. The proposed method is validated in accordance with the ICH guidelines with all of the results within the limits. The detection was carried out with a total runtime of 10.0 min. Optimized chromatographic conditions were shown in table 1 (Hillemacher et al., 2011).

Table 1. Optimized chromatographic conditions

\begin{tabular}{|l|c|}
\hline Parameter & Condition \\
\hline Stationary phase & $\begin{array}{c}\text { Symmetry C18 } \\
(150 \times 4.6 \mathrm{~mm}, 3.5 \mu)\end{array}$ \\
\hline Mobile phase & $\begin{array}{c}0.1 \% \text { OPA: } \\
\text { Acetonitrile }(60: 40)\end{array}$ \\
\hline Injection volume & $10 \mu \mathrm{l}$ \\
\hline Flow rate & $1.0 \mathrm{ml} / \mathrm{min}$ \\
\hline Column temperature & $25^{\circ} \mathrm{C}$ \\
\hline Wave length & $261 \mathrm{~nm}$ \\
\hline Run time & $10.0 \mathrm{~min}$ \\
\hline Retention time of Olanzapine & $4.363 \mathrm{~min}$ \\
\hline Retention time of Samidorphan & $7.732 \mathrm{~min}$ \\
\hline
\end{tabular}

System suitability: The system suitability was performed by injecting standard solution containing $20 \mu \mathrm{g} / \mathrm{ml}$ of Olanzapine and $10 \mu \mathrm{g} / \mathrm{ml}$ of Samidorphan in six replicates. The results indicate that the system suitability parameter is within the limit. System suitability results were shown in table 2 and the standard chromatogram was shown in figure 3 (Fellner 2017).

Figure 3: Chromatogram of system suitability

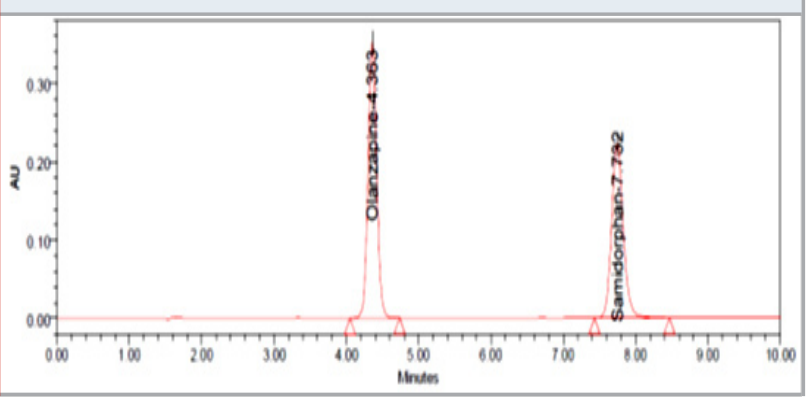

Figure 4: Chromatogram of blank

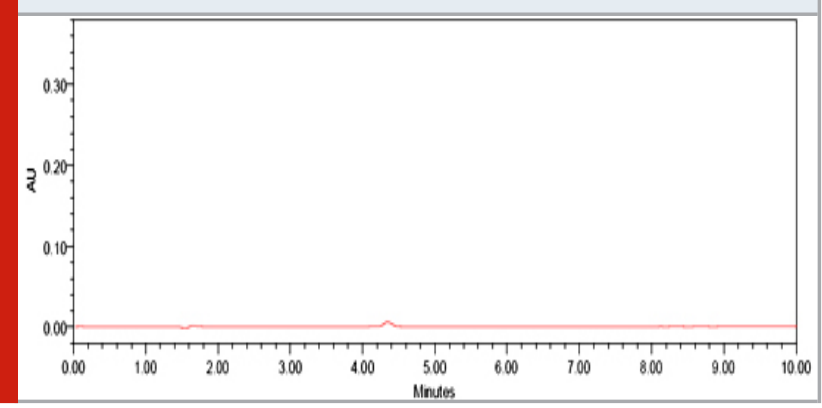

Specificity: There was no interference from blank at the retention time of Olanzapine and Samidorphan. Figure 4 represents the blank chromatogram.

Linearity: Linearity was determined by plotting a calibration curve of peak area against their respective concentration. From this calibration curve it was found that the curve was linear in the range of $2-30 \mu \mathrm{g} / \mathrm{ml}$ of Olanzapine and 1-15 $\mathrm{\mu g} / \mathrm{ml}$ of Samidorphan. The regression equations for calibration curve of Olanzapine was $Y=174856 x+33364(R 2-0.9998)$ and $Y=229090 x$ + 35323 (R2-0.9992) for Samidorphan respectively, the results were shown in table 3 and the calibration plots were shown in figure 5 (Kress 2009; Lee 2019).

Precision: Precision of this method was assessed in terms of intraday (repeatability) and (intermediate precision) variations. The intraday studies were determined by performing six repeated analysis of the sample solution of Olanzapine and Samidorphan on the same day under the same experimental conditions. The intermediate precision of the method was carried out in the same laboratory by studying the analysis with different analyst and different instrument. The method is highly precise as $\%$ RSD values were found to be $<2 \%$. Good recoveries of the drug were obtained at each added concentration, indicating that the method was accurate. Table 4 gives 
the method precision results and the table 5 gives the intermediate precision results (Maric et al., 2016).

Accuracy: The accuracy of the method was performed by calculating the recovery experiments at three levels (50\%, $100 \%$ and 150\%). APIs with concentration 10, 20, $30 \mu \mathrm{g} /$ $\mathrm{ml}$ of Olanzapine and 5, 10, $15 \mu \mathrm{g} / \mathrm{ml}$ of Samidorphan were prepared. The test solution was injected three times for each spike level and assay was performed as per the test method. The recovery results were close to 100\% and also the RSD values were less than $\pm 2 \%$. The percentage recovery, mean and relative standard deviation were calculated. Recovery values demonstrated that the method was accurate within desired range. Accuracy results were shown in table 6 (Sahai \&t Devanna 2021).

\begin{tabular}{|c|c|c|c|c|}
\hline \multirow[t]{2}{*}{ S. No } & \multicolumn{2}{|l|}{ Olanzapine } & \multicolumn{2}{|l|}{ Samidorphan } \\
\hline & Concentration $(\mu \mathrm{g} / \mathrm{ml})$ & Area & Concentration $(\mu \mathrm{g} / \mathrm{ml})$ & Area \\
\hline 1 & 2.00 & 355342 & 1.00 & 212053 \\
\hline 2 & 5.00 & 942105 & 2.50 & 635013 \\
\hline 3 & 10.00 & 1802635 & 5.00 & 1252468 \\
\hline 4 & 20.00 & 3600412 & 10.00 & 2354785 \\
\hline 5 & 25.00 & 4365329 & 12.50 & 2925436 \\
\hline 6 & 30.00 & 5254521 & 15.00 & 3405684 \\
\hline
\end{tabular}

Figure 5: Calibration plots of (A) Olanzapine and (B) Samidorphan

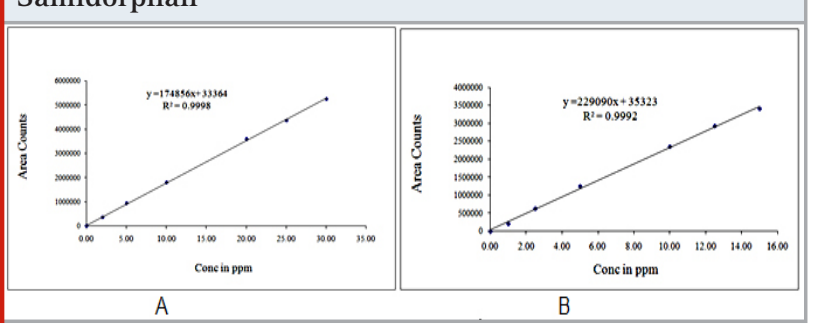

Robustness: Robustness of the chromatographic method was determined by varying flow rate and mobile phase composition. \% RSD was found to be within the acceptable limit. Robustness results were shown in table 7 (Mulhall et al., 2016; Shalini \& Ilango 2021).
Table 4. Results of method precision

\begin{tabular}{|l|c|c|}
\hline S. No. & Area of Olanzapine & Area of Samidorphan \\
\hline 1 & 3635245 & 2365021 \\
\hline 2 & 3501269 & 2345017 \\
\hline 3 & 3542815 & 2315026 \\
\hline 4 & 3546251 & 2385697 \\
\hline 5 & 3536215 & 2345726 \\
\hline 6 & 3524864 & 2311004 \\
\hline Mean & 3656043 & 2344582 \\
\hline Std. dev & 26195.038 & 28673.099 \\
\hline \% RSD & 0.72 & 1.22 \\
\hline
\end{tabular}

\begin{tabular}{|l|c|c|c|}
\hline \multicolumn{4}{|c|}{ Table 5. Results of Intermediate precision } \\
\hline $\begin{array}{l}\text { Area of } \\
\text { Olanzapine }\end{array}$ & $\begin{array}{c}\text { Relative standard } \\
\text { deviation }\end{array}$ & $\begin{array}{c}\text { Area of } \\
\text { Samidorphan }\end{array}$ & $\begin{array}{c}\text { Relative standard } \\
\text { deviation }\end{array}$ \\
\hline 3652130 & 0.68 & 2365201 & 1.16 \\
\hline 3647518 & & 2345187 & \\
\hline 3652894 & & 2365294 & \\
\hline 3621457 & & 2301546 & \\
\hline 3695821 & & 2359612 & \\
\hline 3636259 & & 2316325 & \\
\hline
\end{tabular}

Forced degradation: The proposed method can be used for release and stability studies for effective evaluations and can be considered as stability indicating method. The forced degradation study was carried out according to the ICH requirements include acid, base, oxidation, photo degradation. From the chromatograms it is evident that the selected drugs were stable under the applied stress conditions though the degraded peaks were observed.
Forced degradation study results were shown in table 8 and the degradation chromatograms were shown in figure 6, 7, 8 and 9 respectively (Narula et al., 2014).

However, the study of forced degradation had never been done or published in any journal, it was the first stabilising LC technique for Olanzapine and Samidorphan 
quality control. The devised approach was validated in accordance with ICH requirements and found to be very precise, quick, simple, cost-effective, and sensitive to the specific pharmaceutical dosage form (Seeman 2002).

\begin{tabular}{|c|c|c|c|c|}
\hline Accuracy & $\begin{array}{c}\text { Amount } \\
\text { of } \\
\text { Olanzapine }\end{array}$ & $\begin{array}{c}\% \\
\text { Recovery }\end{array}$ & $\begin{array}{c}\text { Amount } \\
\text { of } \\
\text { Samidorphan }\end{array}$ & $\begin{array}{c}\% \\
\text { Recovery }\end{array}$ \\
\hline 50 & 10 & 99.8 & 5 & 98.9 \\
\hline 100 & 20 & 99.5 & 10 & 99.6 \\
\hline 150 & 30 & 99.9 & 15 & 100.2 \\
\hline
\end{tabular}

Table 7. Results of robustness

\begin{tabular}{|l|c|c|}
\hline Parameter & $\begin{array}{c}\text { \% RSD of } \\
\text { Olanzapine }\end{array}$ & $\begin{array}{c}\text { \% RSD of } \\
\text { Samidorphan }\end{array}$ \\
\hline Flow $(0.8 \mathrm{ml} / \mathrm{min})$ & 0.62 & 1.05 \\
\hline Flow $(1.2 \mathrm{ml} / \mathrm{min})$ & 0.34 & 0.67 \\
\hline Organic phase $(36: 64)$ & 0.98 & 0.86 \\
\hline Organic phase $(44: 56)$ & 0.52 & 0.39 \\
\hline
\end{tabular}

Table 8. Results of forced degradation

\begin{tabular}{|l|c|c|}
\hline \multirow{2}{*}{ Stress parameter } & \multicolumn{2}{|c|}{ \% of degradation } \\
\cline { 2 - 3 } & Olanzapine & Samidorphan \\
\hline $\begin{array}{l}\text { Acid degradation } \\
(1 \mathrm{~N} \mathrm{HCl}+\text { reflux+ 24 hrs) }\end{array}$ & 13.3 & 14.5 \\
\hline $\begin{array}{l}\text { Alkali degradation } \\
(1 \mathrm{~N} \mathrm{NaOH+} \mathrm{reflux+24} \mathrm{hrs)}\end{array}$ & 12.8 & 14.0 \\
\hline $\begin{array}{l}\text { Peroxide degradation } \\
\text { (30\% Peroxide+ reflux+ 24 hrs) }\end{array}$ & 13.7 & 13.2 \\
\hline $\begin{array}{l}\text { Photo degradation } \\
\text { (UV light (200 W h/m2) and } \\
\text { fluorescent light } \\
\text { (1.2 million lux-hrs)) }\end{array}$ & & 11.8 \\
\hline
\end{tabular}

Figure 6: Chromatogram of acid degradation

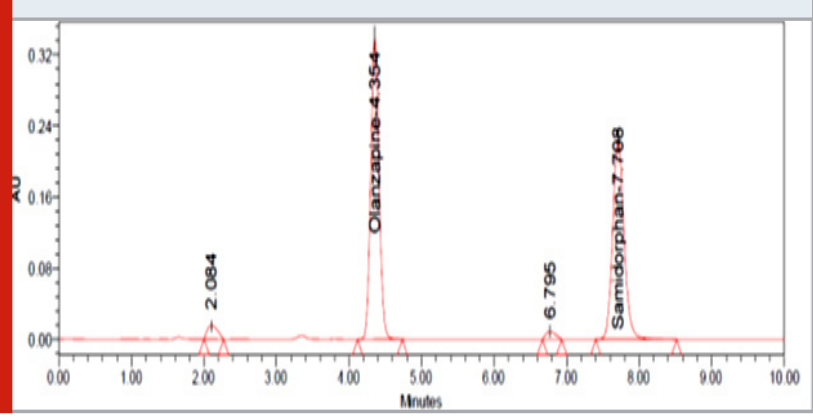

CONCLUSION

In this study a novel, rapid, economical, sensitive and easily available HPLC method was developed for
Figure 7: Chromatogram of alkali degradation

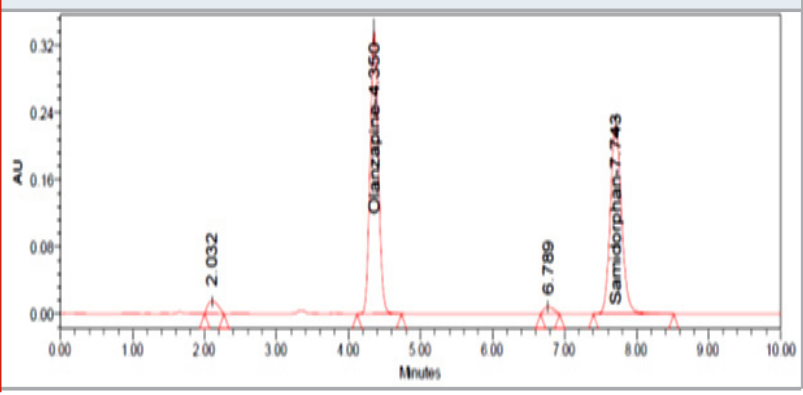

Figure 8: Chromatogram of peroxide degradation

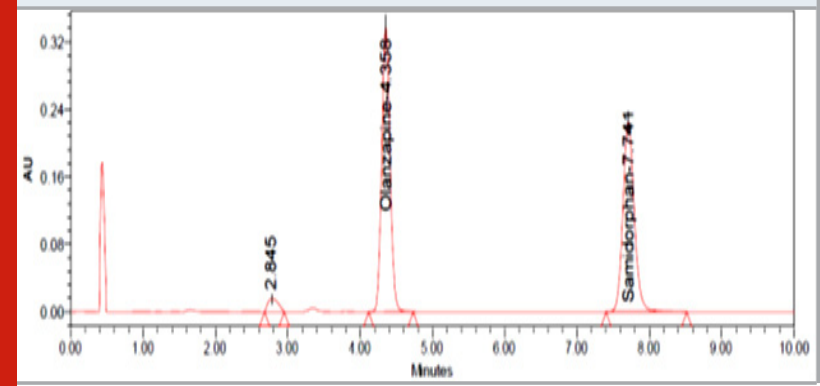

Figure 9: Chromatogram of photo degradation

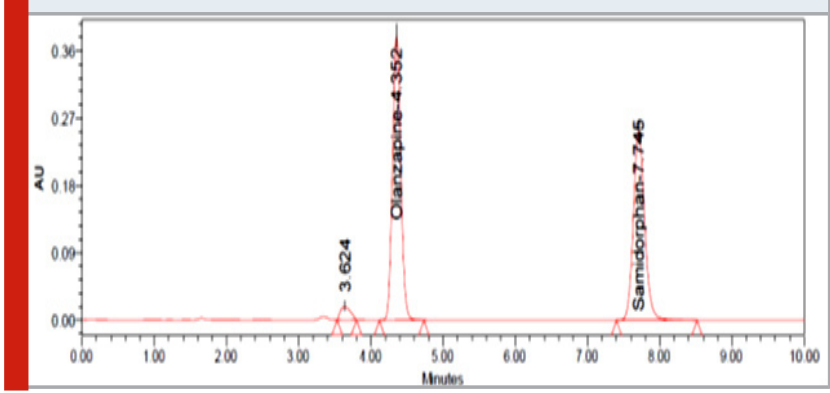

the simultaneous determination of Olanzapine and Samidorphan in bulk and pharmaceutical dosage form. The main advantages of this method are no HPLC methods were reported. In this method shorter run time, low price, accessibility, sensitivity, reliability and reproducibility. These properties are important when a large number of samples are to be analyzed. The validation of all the parameters like linearity, accuracy, 
specificity, robustness, method precision were done and found to be within the acceptable limit. The RSD values for all the parameters were found to be less than $2 \%$, which indicates the validity of the method and the results obtained by this method are in fair agreement. So the proposed method could be easily applied for the routine analysis and the pharmaceutical formulations of Olanzapine and Samidorphan in quality control laboratories without any preliminary separation.

\section{ACKNOWLEDGEMENTS}

I thankful to my guide for encouragement and supporting to finish this research work and also Shree Icon Pharmaceutical Laboratories, Vijayawada for providing laboratory facilities.

Competing Interests: There is no competing of interests

Authors' Contributions: Autor 1 designed the study, performed the statistical analysis, wrote the protocol, and wrote the manuscript. Autor 2 to check the work and review the manuscript.

\section{REFERENCES}

Anderson RI, Becker HC. (2017). Role of the Dynorphin / Kappa Opioid Receptor System in the Motivational Effects of Ethanol. Alcoholism, Clinical and Experimental Research;41(8):1402-1418.

Baizabal-Carvallo JF, Jankovic J. (2012). Movement disorders in autoimmune diseases. Movement Disorders;27(8):935-46.

Carbon M, Hsieh CH, Kane JM, Correll CU. (2017). Tardive Dyskinesia Prevalence in the Period of SecondGeneration Antipsychotic Use: A Meta-Analysis. The Journal of Clinical Psychiatry;78(3):e264-e278.

Chatterjee A. (2014). Glutamate-based magnetic resonance spectroscopy in neuroleptic malignant syndrome. Annals of Indian Academy of Neurology;17(1):123-4. Chisholm, Peter, Anpalahan, Mahesan. (2017). Orthostatic hypotension: pathophysiology, assessment, treatment and the paradox of supine hypertension. Internal Medicine Journal;47(4):370-379.

Correll, Christoph U, Newcomer, John W, Silverman, Bernard, DiPetrillo, Lauren, Graham, Christine, Jiang, Ying, Du, Yangchun, Simmons, Adam, Hopkinson, Craig, McDonnell, David, Kahn, René S., (2020). Effects of Olanzapine Combined With Samidorphan on Weight Gain in Schizophrenia: A 24-Week Phase 3 Study. American Journal of Psychiatry;177(12):1168-1178.

Fellner C. (2017). New Schizophrenia Treatments Address Unmet Clinical Needs. P T;42(2):130-134.

Healy D, Noury LJ, Manginb D. (2018). Enduring sexual dysfunction after treatment with antidepressants, $5 \alpha$-reductase inhibitors and isotretinoin: 300 cases. International Journal of Risk \& Safety in Medicine;29(3):125-134.

Hillemacher T, HeberleinA, Muschler MA, Bleich

S, Frieling H (2011). Opioid modulators for alcohol dependence. Expert Opinion on Investigational Drugs;20(8):1073-86.

Kress HG. (2009). Clinical update on the pharmacology, efficacy and safety of transdermal buprenorphine. Eur J Pain ;13(3):19-30.

Lee B, Elston DM. (2019). The uses of naltrexone in dermatologic conditions. J Am Acad Dermatol;80(6):17461752.

Maric NP, Jovicic MJ, Mihaljevic M, Miljevic C. (2016) Improving Current Treatments for Schizophrenia. Drug Development Research;77(7):357-367.

Mohinish Sahai, Devanna N. (2021). Validated stability indicating HPLC approach for quantifying tricholine citrate and Ciproheptadine simultaneously in syrup forms. Int J App Pharm;13:207-213.

Mulhall JP, Luo X, Zou KH, Stecher V, Galaznik A. (2016). Relationship between age and erectile dysfunction diagnosis or treatment using real-world observational data in the USA. International Journal of Clinical Practice;70(12):1012-1018.

Narula, Harmeet S, Carlson, Harold E. (2014). Gynaecomastia-pathophysiology, diagnosis and treatment. Nature Reviews Endocrinology;10(11):684698.

Owen MJ, Sawa A, Mortensen PB, Schizophrenia. Lancet; 388(10039):86-97. Available: https://doi:10.1016/ S0140-6736(15)01121-6

Qi YX, Xia RY, Wu YS, Stanley F, Huang J, Ye GY. (2014). Larvae of the small white butterfly, Pieris rapae, express a novel serotonin receptor. J Neurochem; 131(6):767-77.

Seeman P. (2002). A typical antipsychotics: mechanism of action. Canadian Journal of Psychiatry; 47(1):2738.

Shalini K, Ilango K. (2021). Development, Evaluation and RP-HPLC method for simultaneous estimation of Quercetin, Ellagic acid and Kaempferol in a poly herbal formulation. Int J App Pharm;13:183-192.

Sri Girija K, Bikshal Babu K, Venkateswara Rao A. (2021). A new high performance liquid chromatography method for the separation and simultaneous quantification of Eptifibatide and its impurities in pharmaceutical injection formulation. Int J App Pharm.;13:165-172.

Strawn JR, Keck PE, Caroff SN. (2007). Neuroleptic malignant syndrome. The American Journal of Psychiatry.;164(6):870-6.

Tandon R, Gaebel W, Barch DM. (2013). Definition and description of schizophrenia in the DSM-5. Schizophrenia Research ;150(1):3-10. 
Tyrer P, Kendall T. (2009). The spurious advance of antipsychotic drug therapy. Lancet;373(9657):4-5. Available: https://doi:10.1016/S0140-6736(08)61765-1 Wentland MP, Lu Q, Lou R, Bu Y, Knapp BI, Bidlack JM., (2005) Synthesis and opioid receptor binding properties of a highly potent 4-hydroxy analogue of naltrexone. Bioorganic \& Medicinal Chemistry Letters;15(8):210710.

Wilden JA, Cohen-Gadol AA (2012). Evaluation of first nonfebrile seizures. American Family Physician.;86(4):334-40.

Xu J, Lu Z, Narayan A. (2017). Alternatively spliced mu opioid receptor $C$ termini impact the diverse actions of morphine. J Clin Invest;127(4):1561-1573.

Zaveri NT, Journigan VB, Polgar WE. (2015). Discovery of the first small-molecule opioid pan antagonist with nanomolar affinity at mu, delta, kappa, and nociceptin opioid receptors. ACS Chem Neurosci;6(4):646-57. 